\title{
GMR
}

\section{Meta-analysis of TP73 polymorphism and cervical cancer}

\author{
H. Feng, L. Sui, M. Du and Q. Wang \\ Department of Obstetrics and Gynecology, Obstetrics and Gynecology Hospital, \\ Fudan University, Shanghai, China \\ Corresponding author: Q. Wang \\ E-mail: flowerinwinds2004@126.com
}

Genet. Mol. Res. 16 (1): gmr16016571

Received September 4, 2016

Accepted October 30, 2016

Published January 23, 2017

DOI http://dx.doi.org/10.4238/gmr16016571

Copyright (C) 2017 The Authors. This is an open-access article distributed under the terms of the Creative Commons Attribution ShareAlike (CC BY-SA) 4.0 License.

ABSTRACT. The aim of this study was to investigate the tumor protein p73 (TP73) G4C14-A4T14 polymorphism and to perform a metaanalysis to assess $T P 73$ expression in cervical cancer and precancerous tissue. Articles containing data regarding TP73 status in cervical cancer patients and healthy controls were retrieved from PubMed, EMBASE, Cochrane, Chinese Biomedical Literature, and China National Knowledge Infrastructure databases. Then, the quality of the studies was evaluated according to inclusion and exclusion criteria. Odds ratios between the case and control groups were used as an effect evaluation index and the RevMan 5.0 software was employed to carry out the meta-analysis. Three independent investigations including 8452 cases of cervical cancer and 8326 healthy controls were included in our study following the application of inclusion and exclusion criteria. PCR genotyping revealed that the TP73 GC/GC genotype produced a 193bp product, while the AT/AT genotype produced a 270-bp fragment, and GC/AT genotype samples produced two fragments of 193 and 270 bp. Meta-analysis showed that TP73 expression in cervical cancer was 
significantly higher than that in normal cervical squamous epithelium $(\mathrm{P}<0.05)$. This elevated expression may play an important role in the occurrence and development of cervical cancer. Therefore, TP73 testing might be useful in the screening and diagnosis of cervical cancer and precancerous lesions.

Key words: Cervical cancer; TP73; Gene polymorphism; Meta-analysis

\section{INTRODUCTION}

Cervical cancer is a frequently observed malignant tumor in gynecology. Worldwide, it is the second most common cancer affecting women, after breast cancer. Annually, more than 500,000 people are diagnosed with cervical cancer across the world, and it causes the death of 275,000 patients (Chen and Yang, 2013; Nekulova et al., 2013). Tumor protein p73 (TP73, also known as $p 73$ ) was reported as the first member of the cancer-suppressor TP53 gene family. Kaghad et al. (1997) first described its discovery during an insulin receptor substrate 1 hybridization screen of a COS cell complementary DNA library. Owing to the similarity between its activity and that of TP53 (also known as p53), including roles in growth retardation and apoptosis, it was given the name "p73" (Kaghad et al., 1997). The aim of the present study was to investigate $T P 73$ expression and its significance in cervical cancer and precancerous tissues by conducting a meta-analysis of the literature.

\section{MATERIAL AND METHODS}

\section{Inclusion and exclusion criteria}

To be included in the meta-analysis, articles had to meet the following criteria: i) cervical cancer diagnoses must have been confirmed by cytopathology or histopathology, and patients must not have received chemotherapy or biological therapy; ii) cases and controls must not have been restricted by factors such as age and race; and iii) healthy controls must have been enrolled at the same period as cervical cancer patients.

The following were excluded from the analysis: i) studies involving patients with liver, kidney, or heart dysfunction, or abnormal hematology; ii) those including participants with severe infections or related diseases, or incomplete pathological information regarding diagnoses; iii) articles with missing data or duplicate reports. This study was approved by the Ethics Committee of Fudan University, Shanghai, China.

\section{Search strategy}

Publications relating to TP73 status in cervical cancer patients and healthy controls were identified by searching through PubMed, Embase, Cochrane Library, China National Knowledge Infrastructure, and Chinese Biomedical Literature databases between January 2010 and June 2014. The following keywords were used: cervical cancer; gene polymorphism; p73; correlation.

Genetics and Molecular Research 16 (1): gmr16016571 


\section{Data extraction}

Two investigators independently carried out the database searches. In cases of disagreement or uncertainty as to whether an article conformed to the above criteria, researchers reached a decision by discussion or the adjudication of a third investigator. The information extracted principally included: the main dataset of the study, general statistical information regarding research object, baseline data comparability, specific and practical interventions, final outcomes, and main research findings. Articles consisting of abstracts only and reviews were excluded.

\section{Inclusion assessment}

The Cochrane Handbook for Systematic Reviews of Interventions version 5.0 was applied for literature evaluation, particularly in regard to: i) the experimental methods used and whether the data were randomly distributed; ii) whether the blind method was adopted; and iii) the presence of dropout or absence of follow-up, and whether intentionto-treat was applied.

\section{Genotyping}

Peripheral venous blood samples $(3 \mathrm{~mL})$ were taken and treated with $0.8 \mathrm{~mL}$ citric acid anticoagulant. DNA was extracted using a genomic DNA purification kit (Sigma-Aldrich, St. Louis, MO, USA), following the manufacturer protocol. Polymerase chain reaction (PCR) with confronting two-pair primers was employed for TP73 G4C14-A4T14 polymorphic classification. The two sets of primers used were as follows: F1: 5'-CCA CGG ATG GGT CTG ATC C-3'; R1: 5'-GGC CTC CAA GGG CAG CTT-3'; F2: 5'-CCT TCC TTC CTG CAG AGC G-3'; R2: 5'-TTA GCC CAG CGA AGG TGG-3'.

\section{Statistical analysis}

RevMan 5.0 software (RevMan, USA) was used for data analysis. Numerical data are reported as odds ratios with $95 \%$ confidence intervals, and P-values below 0.05 were considered statistically significant. The chi-square test was used to assess the heterogeneity of included studies, with $\alpha<0.1$, while $I^{2}$ was applied to quantitatively analyze heterogeneity. Where $\mathrm{P} \geq 0.1$ and $I^{2} \leq 50 \%$, no statistically significant heterogeneity was considered to be presented, and a fixed-effect model was applied.

\section{RESULTS}

\section{Genotype and allele frequency distribution in case and control groups}

Samples from 180 patients and 180 healthy control subjects were collected. TP73 G4C14-A4T14 genotype and allele frequencies showed no significant differences between these groups $(\mathrm{P}>0.05$; Table 1$)$. 
Table 1. TP73 G4C14-A4T14 genotype and allele frequency.

\begin{tabular}{l|c|c|c|c|c}
\hline \multirow{2}{*}{ Group } & \multicolumn{3}{|c|}{ Genotype count (\%) } & \multicolumn{2}{c}{ Allele count (\%) } \\
\cline { 2 - 6 } & GC/GC & GC/AT & AT/AT & GC & AT \\
\hline Controls & $114(63.3)$ & $55(30.6)$ & $11(6.1)$ & $283(78.6)$ & $77(21.4)$ \\
\hline Patients & $103(57.2)$ & $67(37.2)$ & $10(5.6)$ & $273(75.8)$ & $87(24.2)$ \\
\hline
\end{tabular}

\section{TP73 PCR genotyping}

PCR analysis revealed that GC/GC genotype samples produced a 193-bp fragment, while AT/AT samples produced a 270-bp fragment, and GC/AT samples produced two fragments of 193 and $270 \mathrm{bp}$ (Figure 1).

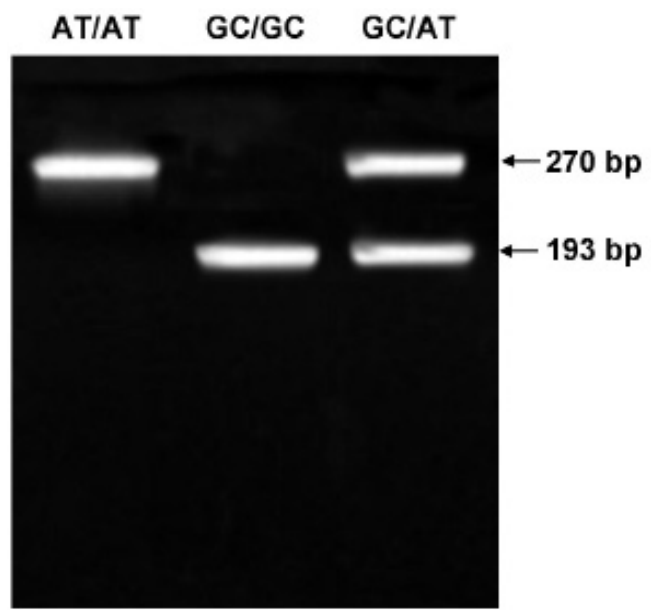

Figure 1. A sequencing image relating to tumor protein $\mathrm{p} 73$ gene polymerase chain reaction products.

\section{Basic characteristics and quality evaluation of the included studies}

Twelve articles were retrieved and 3 articles were selected after the evaluation of their titles, abstracts, and full texts (Craveiro et al., 2012; Jha et al., 2012; Wang et al., 2012a). TP73 status in 8452 cervical cancer patients and 8326 healthy controls was included in our study (Table 2).

Table 2. Data regarding the TP73 G4C14-A4T14 polymorphism meta-analysis.

\begin{tabular}{l|l|l|c|c|c|c|c}
\hline Author & Country & \multirow{2}{*}{ Ethnicity } & \multicolumn{3}{|c|}{ Genotype } & \multirow{2}{*}{ HWE } & \multirow{2}{*}{ Expected power (\%, $\alpha=0.05)$} \\
\cline { 4 - 5 } & & & GC/GC & GC/AT & AT/AT & & \\
\hline Wang et al. (2012a) & China & Asian & $107 / 128$ & $100 / 80$ & $11 / 12$ & 0.913 & 48.5 \\
\hline Craveiro et al. (2012) & Portugal & European & $95 / 119$ & $38 / 48$ & $8 / 9$ & 0.164 & 37.1 \\
\hline Jha et al. (2012) & India & Asian & $71 / 77$ & $28 / 19$ & $2 / 4$ & 0.062 & 25.5 \\
\hline
\end{tabular}

HWE $=$ Hardy-Weinberg equilibrium.

\section{Meta-analysis}

TP73 expression in 8452 cervical cancer patients and 8326 participants with healthy cervixes were used for meta-analysis. The heterogeneity test returned a $\mathrm{P}$ value of 0.86 , therefore a fixed-effect model was applied. A forest plot of the corresponding research results 
was generated. The TP73 AT/GC genotype distribution showed a statistically significant difference between the case and control groups (Figure $2 ; Z=1.85, \mathrm{P}<0.05$ ), indicating that $T P 73$ expression is clearly higher in cervical cancer tissues than in corresponding healthy cervical squamous epithelium.



Figure 2. Meta-analysis of the relationship between the tumor protein p73 (TP73) G4C14-A4T14 polymorphism and cervical cancer. d.f. $=$ degrees of freedom; $\mathrm{OR}=$ odds ratio; $\mathrm{CI}=$ confidence interval.

\section{DISCUSSION}

Oncogene activation is the genetic basis of tumorigenesis, while tumor suppressor genes are capable of inhibiting cell growth and cancerization. TP73, which was the first member of the TP53 gene family associated with human tumors, receives much attention from numerous researchers as a candidate tumor suppressor gene. It is located in the $1 \mathrm{p} 36.2$ to 1 p36.3 region, the deletion of which is often associated with human oncogenesis (DecrionBarthod et al., 2010; Adaramoye et al., 2011; Singh and Singh, 2011; Zhang et al., 2013). Some scholars have found that TP73 is overexpressed in many malignancies, including skin, breast, colorectal, and ovarian cancers, while its expression is relatively low in corresponding healthy tissue (Finzer et al., 2004; Lee et al., 2006; Das Purkayastha and Roy, 2011; Chen et al., 2013). Using immunohistochemical techniques, several reports have revealed that the TP73 $\alpha$ isoform is expressed in non-proliferating normal cervical epithelial cells, and not in proliferating cells (Matsha et al., 2007; Dong et al., 2008; Singh and Singh, 2008; Wakatsuki et al., 2008; Cheung et al., 2010). In addition, TP73 $\alpha$ is minimally expressed, or not at all, in cervical cancer tissue.

Among colon cancer patients, it has been demonstrated that the AT/AT genotype is present at a higher frequency (Liu et al., 2006), while GC/AT and AT/AT genotypes have been correlated with the occurrence of lung cancer and head and neck squamous cell carcinomas (Oh et al., 2008). Craveiro et al. (2004) investigated the relationship between the TP73 2nd exon polymorphism and cervical cancer, and found that the GC/AT genotype in cervical cancer patients is associated with both early menarche and increased parity. Furthermore, polymorphism in the 72nd codon of this gene has been shown to take part in human papilloma

Genetics and Molecular Research 16 (1): gmr16016571 
virus (HPV)-related cervical cancers. Das and Somasundaram (2006) suggested that the HPV E6 protein does not bind to TP73, allowing the latter to play its tumor-suppressive role, and speculated that the relationship between TP73 polymorphism and HPV infection is low. Other scholars have pointed out that the binding of the HPV E6 protein to TP73 may occur upon TP53 mutation, in which case, HPV E6 is able to inhibit TP73 activity (Roperch et al., 2008; Wang et al., 2012b). At present, a firm conclusion regarding the relationship between TP73 2nd exon polymorphism and cervical cancer susceptibility remains to be reached, and further research incorporating large sample sizes is needed.

Meta-analysis is a method enabling the systematic evaluation of results of multiple independent studies with the same research objectives. To a certain degree, it is able to provide a comprehensive analysis using multiple investigations of small sizes to effectively increase sample size and inspection efficiency. It not only strengthens statistical inferences by negating the impact of single small studies, but also synthesizes various research conclusions through its improved estimation of effects, making it more accurate than individual research efforts. With this in mind, in the present study we found that the TP73 AT/GC allelic distribution was significantly different between the case and control groups (Figure $2 ; Z=1.85, \mathrm{P}<0.05$ ) under a fixed-effect model, indicating that the AT allele may elevate cervical cancer risk.

In conclusion, TP73 status may play an important role in the occurrence and development of cervical cancer. Therefore, TP73 testing might be useful in the screening and diagnosis of cervical cancer and precancerous lesions. At present, research into the correlation between $T P 73$ polymorphisms and cervical cancer incidence is lacking, particularly large, multicenter, case-control studies. Using a meta-analysis of the relevant literature, our investigation found that the TP73 AT allele may be associated with cervical cancer tumorigenesis in the Asian population. As the combined sample size was not large, and to achieve a more representative sample of the Asian population, further larger studies are needed to confirm this correlation.

\section{Conflicts of interest}

The authors declare no conflict of interest.

\section{ACKNOWLEDGMENTS}

We thank the anonymous reviewers for reviewing this manuscript.

\section{REFERENCES}

Adaramoye OA, Sarkar J, Singh N, Meena S, et al. (2011). Antiproliferative action of Xylopia aethiopica fruit extract on human cervical cancer cells. Phytother. Res. 25: 1558-1563. http://dx.doi.org/10.1002/ptr.3551

Chen C and Yang RL (2013). A phthalide derivative isolated from endophytic fungi Pestalotiopsis photiniae induces G1 cell cycle arrest and apoptosis in human HeLa cells. Braz. J. Med. Biol. Res. 46: 643-649. http://dx.doi.org/10.1590/1414431X20132979

Chen C, Hu SY, Luo DQ, Zhu SY, et al. (2013). Potential antitumor agent from the endophytic fungus Pestalotiopsis photiniae induces apoptosis via the mitochondrial pathway in HeLa cells. Oncol. Rep. 30: 1773-1781.

Cheung AN, Tsun KL, Ng KM, Szeto E, et al. (2010). P634A4 and TAp73 immunocytochemistry in liquid-based cervical cytology-potential biomarkers for diagnosis and progress prediction of cervical neoplasia. Mod. Pathol. 23: 559-566. http://dx.doi.org/10.1038/modpathol.2009.198

Craveiro R, Costa S, Pinto D, Salgado L, et al. (2004). TP73 alterations in cervical carcinoma. Cancer Genet. Cytogenet. 150: 116-121. http://dx.doi.org/10.1016/j.cancergencyto.2003.08.020

Genetics and Molecular Research 16 (1): gmr16016571 
Craveiro R, Bravo I, Catarino R, Teixeira AL, et al. (2012). The role of p73 G4C14-to-A4T14 polymorphism in the susceptibility to cervical cancer. DNA Cell Biol. 31: 224-229. http://dx.doi.org/10.1089/dna.2011.1294

Das S and Somasundaram K (2006). Therapeutic potential of an adenovirus expressing p73 beta, a p53 homologue, against human papilloma virus positive cervical cancer in vitro and in vivo. Cancer Biol. Ther. 5: 210-217. http://dx.doi. org/10.4161/cbt.5.2.2402

Das Purkayastha BP and Roy JK (2011). Molecular analysis of oncogenicity of the transcription factor, BRN3A, in cervical cancer cells. J. Cancer Res. Clin. Oncol. 137: 1859-1867. http://dx.doi.org/10.1007/s00432-011-1059-0

Decrion-Barthod AZ, Bosset M, Plissonnier ML, Marchini A, et al. (2010). Sodium butyrate with UCN-01 has marked antitumour activity against cervical cancer cells. Anticancer Res. 30: 4049-4061.

Dong W, Arpin C, Accardi R, Gissmann L, et al. (2008). Loss of p53 or p73 in human papillomavirus type 38 E6 and E7 transgenic mice partially restores the UV-activated cell cycle checkpoints. Oncogene 27: 2923-2928. http://dx.doi. org/10.1038/sj.onc.1210944

Finzer P, Krueger A, Stöhr M, Brenner D, et al. (2004). HDAC inhibitors trigger apoptosis in HPV-positive cells by inducing the E2F-p73 pathway. Oncogene 23: 4807-4817. http://dx.doi.org/10.1038/sj.onc.1207620

Jha AK, Nikbakht M, Jain V, Sehgal A, et al. (2012). Promoter hypermethylation of p73 and p53 genes in cervical cancer patients among north Indian population. Mol. Biol. Rep. 39: 9145-9157. http://dx.doi.org/10.1007/s11033-012-1787-5

Kaghad M, Bonnet H, Yang A, Creancier L, et al. (1997). Monoallelically expressed gene related to p53 at 1p36, a region frequently deleted in neuroblastoma and other human cancers. Cell 90: 809-819. http://dx.doi.org/10.1016/S0092$\underline{8674(00) 80540-1}$

Lee JJ, Kim S, Yeom YI and Heo DS (2006). Enhanced specificity of the p53 family proteins-based adenoviral gene therapy in uterine cervical cancer cells with E2F1-responsive promoters. Cancer Biol. Ther. 5: 1502-1510. http:// dx.doi.org/10.4161/cbt.5.11.3300

Liu SS, Chan KY, Cheung AN, Liao XY, et al. (2006). Expression of deltaNp73 and TAp73alpha independently associated with radiosensitivities and prognoses in cervical squamous cell carcinoma. Clin. Cancer Res. 12: 3922-3927. http:// dx.doi.org/10.1158/1078-0432.CCR-05-2573

Matsha T, Donninger H, Erasmus RT, Hendricks D, et al. (2007). Expression of p53 and its homolog, p73, in HPV DNA positive oesophageal squamous cell carcinomas. Virology 369: 182-190. http://dx.doi.org/10.1016/j.virol.2007.07.025

Nekulova M, Holcakova J, Nenutil R, Stratmann R, et al. (2013). Characterization of specific p63 and p63-N-terminal isoform antibodies and their application for immunohistochemistry. Virchows Arch. 463: 415-425. http://dx.doi. org/10.1007/s00428-013-1459-4

Oh YK, Lee HJ, Jeong MH, Rhee M, et al. (2008). Role of activating transcription factor 3 on TAp73 stability and apoptosis in paclitaxel-treated cervical cancer cells. Mol. Cancer Res. 6: 1232-1249. http://dx.doi.org/10.1158/15417786.MCR-07-0297

Roperch JP, El Ouadrani K, Hendrix A, Emami S, et al. (2008). Netrin-1 induces apoptosis in human cervical tumor cells via the TAp73alpha tumor suppressor. Cancer Res. 68: 8231-8239. http://dx.doi.org/10.1158/0008-5472.CAN-08-1483

Singh M and Singh N (2008). Induction of apoptosis by hydrogen peroxide in HPV 16 positive human cervical cancer cells: involvement of mitochondrial pathway. Mol. Cell. Biochem. 310: 57-65. http://dx.doi.org/10.1007/s11010$\underline{007-9665-5}$

Singh M and Singh N (2011). Curcumin counteracts the proliferative effect of estradiol and induces apoptosis in cervical cancer cells. Mol. Cell. Biochem. 347: 1-11. http://dx.doi.org/10.1007/s11010-010-0606-3

Wakatsuki M, Ohno T, Iwakawa M, Ishikawa H, et al. (2008). p73 protein expression correlates with radiation-induced apoptosis in the lack of 533 response to radiation therapy for cervical cancer. Int. J. Radiat. Oncol. Biol. Phys. 70: 1189-1194. http://dx.doi.org/10.1016/j.ijrobp.2007.08.033

Wang L, Gao R and Yu L (2012a). Combined analysis of the association between p73 G4C14-to-A4T14 polymorphisms and cancer risk. Mol. Biol. Rep. 39: 1731-1738. http://dx.doi.org/10.1007/s11033-011-0913-0

Wang Z, Sturgis EM, Guo W, Song X, et al. (2012b). Association of combined p73 and p53 genetic variants with tumor HPV16-positive oropharyngeal cancer. PLoS One 7: e35522. http://dx.doi.org/10.1371/journal.pone.0035522

Zhang X, Li X, Wu Z, Lin F, et al. (2013). The p73 G4C14-to-A4T14 polymorphism is associated with risk of lung cancer in the Han nationality of North China. Mol. Carcinog. 52: 387-391. http://dx.doi.org/10.1002/mc.21869

Genetics and Molecular Research 16 (1): gmr16016571 